\title{
Relationship between Insight and Spirituality in Individuals with Schizophrenia
}

\author{
Mr. Deepshri Phukan ${ }^{1 *}$, Dr. Maitreyee Dutta ${ }^{2}$
}

\section{ABSTRACT}

The primary aim of this study was to understand the relationship among insight into illness and spirituality in patients with schizophrenia. Patients diagnosed with schizophrenia according to ICD-10 (F20-F20.9) were approached and explained about the purpose of the study. Initially patients were screened out on BPRS to rule out severe psychopathology. Only those patients who fulfilled the inclusion and exclusion criteria and provided written informed consent were recruited. Sociodemographic and clinical details were obtained from the patients, care givers and treatment records. Following this, patients were asked to complete the Birchwood's Insight Scale (BIS) and FACIT-SP-12 scale. Applied statistical methods were Descriptive statistics, Nonparametric test (Mann-Whitney U- test and Kruskal-Wallis test) and Pearson product moment correlation method. In this study significant negative correlation was found between total insight scores and "peace" domain of spirituality; on the other hand total spirituality score was significantly negatively correlated with "awareness of disease" domain of insight. The domain of "awareness of disease” also negatively correlated with "peace” domain of spirituality.

Keywords: Schizophrenia, Insight, Spirituality

Consensus has emerged that the concept of insight is both a multidimensional and a continuous construct. Amador and David (1998) provided a multidimensional concept of insight that includes- awareness of mental illness, understanding of the social consequences of disorder, awareness of the need of the treatment, awareness of specific sign and symptoms of the disorder and attribution of the symptoms to the disorder. Earlier studies use categorical approach, dividing patients into those with and without insight and those with some or partial insight. Recent studies have involved in studying insight as a continuous process rather than the all-ornone or partial concept. Insight is assessed in graded manner and structured schedules are used to

\footnotetext{
${ }^{1}$ Clinical Psychologist, Dept. of Clinical Psychology, LGBRIMH, Tezpur, Assam, India

${ }^{2}$ Associate Professor, Dept. of Clinical Psychology, LGBRIMH, Tezpur, Assam, India

*Responding Author
}

Received: January 29, 2017; Revision Received: February 17, 2017; Accepted: February 24, 2017

(C) 2017 Phukan D, Dutta M; licensee IJIP. This is an Open Access Research distributed under the terms of the Creative Commons Attribution License (www.creativecommons.org/licenses/by/2.0), which permits unrestricted use, distribution, and reproduction in any Medium, provided the original work is properly cited. 


\section{Relationship between Insight and Spirituality in Individuals with Schizophrenia}

capture component of insight quantitatively. Insight is regarded as a continuum of thinking and feeling, affected by numerous internal and external variables (Singh.K, Anup.P, 2008).

Insight Scale (IS), which is used in this study, devised by Birchwood et al (1994) is a self report measure to assess insight through three dimension- awareness of symptoms, awareness of disease and need for treatment.

There is many view point regarding the meaning of 'spirituality' and its relationship with religion. Spirituality refers to any experience or way of life, religious or otherwise, which can help the person to detach from the trivia, transcend and reach a calming and reassuring level of connectedness, meaning and purpose. Koenig (2009) stated that religion is conceptualized as an organized and established set of sacred beliefs, practices and rituals practiced by a group of people, where as spirituality is often interpreted as a more individual and personal structured set of beliefs. Religiosity refers to the degree of participation or adherence to the beliefs and practices of an organized religion (Mueller et al, 2001). Spiritual well-being relates to life affirming relationships, creative energy, the wholeness of an individual's spirit and unifying dimension of health, faith in a High power, enhancement of the individual's inner resources and inner strength (Young C, Koopsen C. 2004).

In this study, for the purpose of measurement of spirituality The Functional Assessment of Chronic Illness Therapy- Spiritual Wellbeing Scale is used which consists of subscales- faith, meaning and peace.

The relationship between insight and quality of life is paradoxical. A Karaow and FG Pajonk (2008) found contradictory result regarding the relationship between insight in to illness and quality of life in patients with schizophrenia. Previous studies found an inverse or no significant association; recent studies reported greater insight is significantly associated with an increase in depression and poor subjective quality of life. They summarized that patients with good insight might realize their restriction more clearly and the stigma of being mentally ill and the need for treatment or hospitalization are psychological strains. (Karaw A, Pajonk FG, 2006). Lack of insight seems to place person at risk for rejecting helpful treatments, poor social and vocational function. On the other hand awareness of illness puts persons at risk for depression, low selfesteem and helplessness (Lysaker et al, 2009). Another one factor is stigma. Lysaker et al (2007) have suggested that internalized stigma may be the factor which mitigates the impact of whether insight can lead to improved quality of life.

Concerning this conflict between insight and quality of life, one possible explanation is the

meaning that attached to schizophrenia by the patient. Insight is a personal construct that is established within a life story; in Jaspers' words, it is within the knowledge of self-existence. Patient gives meaning to any illness in the construct of meaning of life. From transcendental 
point of view, there are two forms of living- one in which events follow one another without noticing them, without stopping to think over them. Another one is when life itself is perceived deep inside; through crisis human being start to know what human beings are. If a schizophrenic patient lives through a second type of living then his/her meaning attached to the illness will be different which will lead to a different quality of life than the others who lives first type of living. In terms of loss in schizophrenia, if it focuses on the remaining of the strengths of the patient rather than on the lost or what is no longer possible then the patient's quality of life will take a new form. Recovery will be a meaning making process. This meaning making process take the person as a whole person, as the quality of life of a patient evaluate the patient as a whole person. Regarding this whole perspective new formulation has emerged as 'Biopsychosociospiritual' formulation (Josephson, A.M, Peteet, J.R 2004). Existential themes added by spiritual approach involved hope, identity, morality, meaning and autonomy. This spiritual approach by referring the person as a whole person can give an answer to the paradox between the insight and quality of life in schizophrenic patient.

Spirituality seems to be a coping mechanism in mental illnesses. Spirituality relates to positive outcome and improves wellbeing of patients. Review of literature reveals that there is almost nonexistence of study regarding the relationship between insight and spirituality.

\section{METHODOLOGY}

Need of the study

Here, the need is to assess the relationship between these variables, because literature suggests that there is almost a non-existence of literature regarding the relationship between insight and spirituality, and the dearth of application of spiritual dimensions in clinical practice of mental health as well as in research.

\section{Aims and objective}

The primary aim of this study was to understand the relationship among insight into illness and spirituality in patients with schizophrenia who were undergoing treatment as outpatients in LGBRIMH, Tezpur, Assam. Objectives: To examine the Socio-Demographic characteristics of the patients' and to find out the relationship between Insight and Spirituality in patients with schizophrenia.

\section{Operational Definitions}

Insight: Operationally insight is conceptualized as patient's awareness to the illness as well as patient's awareness about the symptoms. Insight comprises patient's awareness to treatment adherence and willingness to adhere to the treatment process. Insight is defined as consisting of three dimensions- awareness of illness, the capacity to relabel psychotic experiences as abnormal and treatment compliance. 
Spirituality: It is defined as personal quest for understanding awareness to ultimate questions about life, about meaning and about relationship with the sacred or transcendent which might or might not be related to religious rituals. Patient's feelings of inner peace, meaning of life and their faith on transcendent were comprised within the definition of spirituality in this study. In various literatures spirituality and religiousness were used synonymously, so in this study these two terms used as synonymously most of the time.

Schizophrenia: Here schizophrenia is defined according to ICD-10 guidelines. Schizophrenic disorders are characterized in general by fundamental and characteristic distortion of thinking and perception and by inappropriate or blunted affect.

\section{Research Design}

The research design employed was descriptive and cross-sectional design. Setting: The study was conducted at Lokopriya Gopinath Bordoloi Regional Institute of Mental Health (LGBRIMH), Tezpur, Assam, Out Patient Department.

\section{Sample and Sampling Method}

The population was consisting of all male and female persons between 18 to 60 years diagnosed with schizophrenia (ICD-10, DCR-10; F20-20.9). Sixty persons diagnosed with Schizophrenia (F20-20.9) according to ICD-10 (DCR-10) who's BPRS scores was found to be below 31 were taken using purposive sampling method.

\section{Inclusion Criteria}

1. Diagnosed as per ICD-10(DCR-10) guidelines (F20-F20.9), (WHO,1993)

2. Those who are maintaining treatment on OPD basis at LGBRIMH.

3. Score below 31 in BPRS.

4. Between 18 to 60 years of age.

5. Patients of both sexes.

6. Patients with an education background of minimum of eighth standard.

\section{Exclusion Criteria}

1. History of substance abuse.

2. Presence of organic brain disorder

3. Mental retardation.

4. Presence of psychopathology interfering in eliciting reliable information.

\section{Description of Tools}

SOCIO-DEMOGRAPHIC AND CLINICAL DATA SHEET: It is semi structured and self prepared Performa contains information about sociodemographic variables like age, education, marital status, religion, ethnicity, community, employment status, domicile background, family 
type and socioeconomic status. It also contains two clinical variables like age at onset of illness and duration of illness. BRIEF PSYCHIATRIC RATING SCALE (BPRS): The Brief Psychiatric Rating Scale (BPRS) Expanded version 4.0 is a 24 item rating scale constructed by Overall et.al (1962) measuring positive symptoms, general psychopathology and affective symptoms. Each item is rated on a 7 point scale ( $1=$ not present to $7=$ extremely severe). The reliability for the original version (Overall \& Gorham, 1962), was reported to be inter-rater reliability of 0.560.87 .

FACIT-SP-12(Version 4) Scale (Functional Assessment of Chronic Illness TherapySpiritual Wellbeing): The FACIT-SP was developed in the 1990's to address the need for a brief, broad measure of spiritual well being with content not limited to any one religious or spiritual tradition. It consists of 12 items and three sub-domains of spiritual well being, which helps facilitate an in depth exploration of the components that constitute spiritual well being (peace, meaning and faith). All of the FACIT-SP questionnaires were designed for self administration and use a 5 point Likert type scale to measure patient reported health related quality of life ( $0=$ not at all, $1=$ a little bit, $2=$ somewhat, $3=$ quite a bit and $4=$ very much). The recall period for each question is seven days. Questions were written at the fourth grade-reading level as measured by the Lexile Framwork. The scale also has the option to complete the questionnaire by interview which decreases the burden for patients whose condition or mood preclude them from completing the questionnaire on their own, although this may increase the completion time. The internal reliability of the subscales was found to be $\alpha=0.81-0.88$ and there were moderate to strong correlation between the total FACIT-SP subscales score and the other Health Related Quality of Life Scales.

BIRCHWOOD INSIGHT SCALE (IS): Birchwood's Insight Scale is a self-report insight scale for psychosis. This scale consists of eight uncomplicated and direct statements that the patient rates on a 3-point scale (agree, disagree, unsure) that can be completed quickly by even seriously disturbed patient. The test items were designed to assess each of the three dimensions of insight advocated by David (1990): Awareness of Illness, Ability to relabeled Symptoms and Awareness of need for Treatment. Reliability and validity of the Birchwood's Insight Scale are found to have internal consistency ( Cronbach's alpha $=.75$ ) and test-retest reliabilities (.90) over a one week interval. The scale has adequate construct, criterion and concurrent validities and sensitivity to individual differences and changes.

\section{Procedure}

Patients diagnosed with schizophrenia according to ICD-10 (F20-F20.9) were approached and explained about the purpose of the study. Initially patients were screened out on BPRS to rule out severe psychopathology and recruited who scored below 31. Only those patients who fulfilled the inclusion and exclusion criteria and provided written informed consent were recruited. Sociodemographic and clinical details were obtained from the patients, care givers and 


\section{Relationship between Insight and Spirituality in Individuals with Schizophrenia}

treatment records. Following this, patients were asked to complete the Birchwood's Insight Scale (BIS) and FACIT-SP-12 scale. Informed consents were obtained by assuring the confidentiality of information.

Statistical analysis: Statistical analyses were done using Statistical Package for Social Science (SPSS) version 20. For sociodemographic and clinical variables, frequencies and percentages were computed for discontinuous variables (e.g- gender, religion, education etc.) and means and standard deviations were computed for continuous variables (age, duration of illness, and age at onset). Descriptive analysis done and means and standard deviations were calculated for scores on BIS and FACIT-SP-12. Non-parametric tests- Kruskal Wallis test and Mann Whitney U test, were used to study differences in scores of two scales (BIS and FACIT-SP-12) with regard to Gender, Education, Marital Status, Religion, Ethnicity, Community, Employment, Domicile, Family type and Scocioeconomic Status. Pearson product moment correlation test was used to study the relationship between the scores of two scales and age, age at onset and duration of illness. Pearson's product moment correlation test was used to study the relationship among various domains of BIS and FACIT-SP-12.

\section{RESULTS}

Applied statistical methods were Descriptive statistics, Non-parametric test (Mann-Whitney Utest and Kruskal-Wallis test) and Pearson product moment correlation method.

All the results of data interpretation were summarized in the following headings:

1. Descriptive analysis and variable association between insight and sociodemographic and clinical variables (table 1 ).

2. Descriptive analysis and variable association between spirituality and sociodemographic and clinical variables (table 2).

3. Relationship between Insight and Spirituality (table 3).

The mean age of the participants was 33.42 years. Most of the patients were male (81.7\%), while female were $18.3 \%$. Majority of the participants belonged to the educational level of viii-X (65\%). Among all the participants 58.3\% were unmarried and 30\% were married participants, while $3.3 \%$ and $8.3 \%$ were separated and divorced respectively. Most of the participants belonged to the Hindu religion (81.7\%) and most of them were nontribal (86.7\%). Unemployed participants were more than the employed (41.7\% and $10 \%$ respectively). In the category of professional/others, participants were more (48.3\%) than the other categories which comprise all the participants who are living by cultivating on their own land and involving professional work. Majority were from rural background (91.7\%) and from nuclear family (60\%). While there were no participants from upper socioeconomic status most of them were from low middle socioeconomic status (31.7\%). The mean age of onset was 25.53 years and the mean total duration of illness was 7.98 years. 


\section{Relationship between Insight and Spirituality in Individuals with Schizophrenia}

Statistically significant differences were found between two domicile status (urban and rural) and insight $(\mathrm{P}=.025)$. We observed significant negative correlation between age and spirituality $(\mathrm{r}=$ $.293, p=.023$ ) (Table-2). Significant differences were found between two categories of ethnicity (tribal, nontribal) and spirituality $(\mathrm{P}=.054)$. Spirituality was significantly different in various levels of socioeconomic status $(\mathrm{P}=.044)($ table-2).

Table 3 shows that among the three domains of Insight only Awareness of Disease had significant negative correlation with the domain of Peace of FACIT-SP-12 ( $\mathrm{r}=-.485, \mathrm{P}=.000)$ and total FACIT-SP-12 spirituality scores ( $\mathrm{r}=-.327, \mathrm{P}=.011)$. On the other way the domain of Peace had significant negative correlation with total Insight scores $(r=-.377, \mathrm{P}=.003)$. There was no significant correlation between total Insight scores and total FACIT-SP-12 Spirituality scores, although table shows negative correlation.

Table 1: Descriptive analysis and variable association between insight and sociodemographic and clinical variables

\begin{tabular}{|c|c|c|c|}
\hline Variable & Mean & SD & $\begin{array}{l}\text { P value } \\
\end{array}$ \\
\hline Age & 33.42 & 7.962 & $\mathrm{r}=.110$ \\
\hline Age of onset & 25.53 & 7.15 & $\mathrm{r}=.183$ \\
\hline Total duration of illness & 7.98 & 4.96 & $\mathrm{r}=-.065 \quad \mathrm{p}=.624$ \\
\hline Variable & n (\%) & Insight & P value \\
\hline \multicolumn{4}{|l|}{ Sex } \\
\hline Male & $49(81.7 \%)$ & 29.80 & $.540 ¥$ \\
\hline female & $11(18.3 \%)$ & 33.64 & \\
\hline \multicolumn{4}{|l|}{ Education } \\
\hline viii-x & $39(65 \%)$ & 30.06 & $205 \pm$ \\
\hline $10+2$ & $13(21.7 \%)$ & 36.50 & \\
\hline Graduate & $8(13.3 \%)$ & 22.88 & \\
\hline \multicolumn{4}{|l|}{ Marital status } \\
\hline Unmarried & $35(58.3 \%)$ & 26.90 & $.152 \pm$ \\
\hline Married & $18(30.0 \%)$ & 38.28 & \\
\hline Separated & $2(3.3 \%)$ & 28.00 & \\
\hline Divorced & $5(8.3 \%)$ & 28.70 & \\
\hline \multicolumn{4}{|l|}{ Religion } \\
\hline Hindu & $49(81.7 \%)$ & 30.37 & $.900 ¥$ \\
\hline Islam & 11(18.3\%) & 31.09 & \\
\hline \multicolumn{4}{|l|}{ Ethnicity } \\
\hline Tribal & $8(13.3 \%)$ & 28.88 & $.775 ¥$ \\
\hline Non-tribal & $52(86.7 \%)$ & 30.75 & \\
\hline \multicolumn{4}{|l|}{ Employment } \\
\hline Unemployed & $25(41.7 \%)$ & 32.70 & $.640 \pm$ \\
\hline Employed & $6(10 \%)$ & 31.75 & \\
\hline Professional/others & 29(48.3\%) & 28.34 & \\
\hline
\end{tabular}


Relationship between Insight and Spirituality in Individuals with Schizophrenia

\begin{tabular}{|l|c|c|c|}
\hline Domicile status & \multicolumn{3}{|l|}{} \\
\hline Urban & $5(8.3 \%)$ & 14.10 & $\mathbf{. 0 2 5} ¥$ \\
\hline Rural & $55(91.7 \%)$ & 31.99 & \\
\hline Family structure & \multicolumn{3}{|l|}{} \\
\hline Nuclear & $36(60 \%)$ & 32.11 & $.375 ¥$ \\
\hline Joint & $24(40 \%)$ & 28.08 & \\
\hline Socio-economic status & \multicolumn{3}{|l|}{} \\
\hline Low & $17(28.3 \%)$ & 37.09 & $.199 \pm$ \\
\hline Upper low & $14(23.3 \%)$ & 27.11 & \\
\hline Low middle & $19(31.7 \%)$ & 25.79 & \\
\hline Upper middle & $10(16.7 \%)$ & 33.00 & \\
\hline
\end{tabular}

$¥$ Mann-Whitney U test, \pm Kruskal-Wallis test.

Table 2: Descriptive analysis and variable association between spirituality and sociodemographic and clinical variables

\begin{tabular}{|c|c|c|c|}
\hline Variable & Mean & SD & P value \\
\hline Age & 33.42 & 7.962 & $\mathrm{r}=-.293$ \\
\hline Age of onset & 25.53 & 7.15 & $\mathrm{r}=-.197$ \\
\hline Total duration of illness & 7.98 & 4.96 & $\mathrm{r}=-.202$ \\
\hline Variable & n (\%) & Spirituality & $\mathbf{P} \sim$ value \\
\hline \multicolumn{4}{|l|}{ Sex } \\
\hline Male & $49(81.7 \%)$ & 30.11 & $.716 ¥$ \\
\hline female & $11(18.3 \%)$ & 32.23 & \\
\hline \multicolumn{4}{|l|}{ Education } \\
\hline viii-x & $39(65 \%)$ & 32.04 & $.487 \pm$ \\
\hline $10+2$ & $13(21.7 \%)$ & 25.38 & \\
\hline Graduate & $8(13.3 \%)$ & 31.31 & \\
\hline \multicolumn{4}{|l|}{ Marital status } \\
\hline Unmarried & $35(58.3 \%)$ & 31.34 & $.956 \pm$ \\
\hline Married & $18(30.0 \%)$ & 28.69 & \\
\hline Separated & $2(3.3 \%)$ & 28.75 & \\
\hline Divorced & $5(8.3 \%)$ & 31.80 & \\
\hline \multicolumn{4}{|l|}{ Religion } \\
\hline Hindu & 49(81.7\%) & 31.70 & $.259 ¥$ \\
\hline Islam & $11(18.3 \%)$ & 25.14 & \\
\hline \multicolumn{4}{|l|}{ Ethnicity } \\
\hline Tribal & $8(13.3 \%)$ & 41.56 & $.054 ¥$ \\
\hline Non-tribal & $52(86.7 \%)$ & 28.80 & \\
\hline \multicolumn{4}{|l|}{ Employment } \\
\hline Unemployed & $25(41.7 \%)$ & 29.40 & $.898 \pm$ \\
\hline Employed & $6(10 \%)$ & 29.92 & \\
\hline Professional/others & $29(48.3 \%)$ & 31.57 & \\
\hline \multicolumn{4}{|l|}{ Domicile status } \\
\hline Urban & $5(8.3 \%)$ & 34.80 & $.565 \pm$ \\
\hline
\end{tabular}

(C) The International Journal of Indian Psychology, ISSN 2348-5396 (e)| ISSN: 2349-3429 (p) | 60 
Relationship between Insight and Spirituality in Individuals with Schizophrenia

\begin{tabular}{|l|l|l|l|}
\hline Rural & 55(91.7\%) & 30.11 & \\
\hline Family structure & \multicolumn{3}{|l|}{} \\
\hline Nuclear & $36(60 \%)$ & 29.53 & $.595 ¥$ \\
\hline Joint & $24(40 \%)$ & 31.96 & \\
\hline Socio-economic status & \multicolumn{3}{|l|}{} \\
\hline Low & $17(28.3 \%)$ & 25.62 & $\mathbf{. 0 4 4} \pm$ \\
\hline Upper low & $14(23.3 \%)$ & 23.04 & \\
\hline Low middle & $19(31.7 \%)$ & 38.11 & \\
\hline Upper middle & $10(16.7 \%)$ & 34.80 & \\
\hline
\end{tabular}

$¥$ Mann-Whitney U test, \pm Kruskal-Wallis test.

Table 3: Relationship between Insight and Spirituality

\begin{tabular}{|l|l|l|l|l|}
\hline Spirituality Insight & Meaning & Peace & Faith & Total Spirituality score \\
\hline Symptoms & $\mathrm{r}=-.038$ & $\mathrm{r}=-.103$ & $\mathrm{r}=.163$ & $\mathrm{r}=.010$ \\
& $\mathrm{p}=.774$ & $\mathrm{p}=.432$ & $\mathrm{p}=.204$ & $\mathrm{p}=.940$ \\
\hline Disease & $\mathrm{r}=-.166$ & $\mathbf{r}=-. \mathbf{4 8 5}$ & $\mathrm{r}=-.083$ & $\mathbf{r}=-.327$ \\
& $\mathrm{p}=.205$ & $\mathbf{p}=. \mathbf{0 0 0}$ & $\mathrm{p}=.531$ & $\mathbf{p}=. \mathbf{0 1 1}$ \\
\hline Treatment & $\mathrm{r}=060$ & $\mathrm{r}=-.175$ & $\mathrm{r}=.116$ & $\mathrm{r}=-.003$ \\
& $\mathrm{p}=.649$ & $\mathrm{p}=.181$ & $\mathrm{p}=.377$ & $\mathrm{p}=.983$ \\
\hline Total Insight score & $\mathrm{r}=-.087$ & $\mathbf{r}=-.377$ & $\mathrm{r}=.089$ & $\mathrm{r}=-.170$ \\
& $\mathrm{p}=.507$ & $\mathbf{p}=\mathbf{. 0 0 3}$ & $\mathrm{p}=.498$ & $\mathrm{p}=.195$ \\
\hline
\end{tabular}

Significant $\mathrm{P}<0.05$

\section{DISCUSSION}

The participants were aged between 20 to 53 years of age. Regarding the relationship between age and the two study variables results indicate that increasing age has significant negative correlation with spirituality. It suggests that younger age group has more meaning, faith and peace in life; as age increases spiritual wellbeing decreases. In a study done by Stojkovic et al (2012) found that faith was more present in respondents from the youngest age group and their condition greatly strengthened their faith or spiritual beliefs. Youngest age group had a strong attitude that everything would be fine regardless of the disease. As a person progresses through the stages of a chronic disease, his or her desire for death often elevates, and that for many people, there could be an associated decline in spiritual well-being (Jason M. Bredle et al, 2011). There was no difference between male and female in any of the two study variables. In this study significant difference was found among various socioeconomic status concerning spirituality. Income is an important parameter in socio economic status. Ruesh et al (2004) mentioned that income was markedly and negatively related to subjective quality of life. Social support explains the better subjective quality of life of severe mentally ill people. Significant difference was found among various domicile background concerning insight, as opposed to previous study, with highest mean rank to rural background. It should be interpreted cautiously as there were few patients from urban and semi urban background compared to rural background. In this study age 
of onset of illness and duration of illness are selected as clinical variables but no significant relationship found with two study variables.

Regarding the relationship between insight and spirituality the literature is almost non-existent. In this study no significant correlation was found between total insight scores and total spirituality scores. But significant negative correlation was found between total insight scores and "peace" domain of spirituality; on the other hand total spirituality score was significantly negatively correlated with "awareness of disease" domain of insight. The domain of awareness of disease also negatively correlated with peace domain of spirituality. This negative relationship can be explained by associated depression and stigma in schizophrenia diagnosis. As the awareness of illness leads to depressive symptoms and stigma can make the diagnosis of schizophrenia more distressing to the patient (Ampalan, 2012) and disturbs the inner peace. Lack of insight is characteristic features of schizophrenia, but on the path of spiritual growth insight is ever present (Patil.SS, 2007)

\section{Limitation of the study}

As a cross sectional study and as the sample size is small the results of the study might not be applied to a large scale population. The treatment pattern of the patients is not considered so it may color the results. There was no representative from upper socioeconomic status and illiterate are not included so generalization to large scale is not suitable for this study. The samples are taken from outpatient department so the results cannot be generalized for long staying in-patients who are not functioning enough. Above all it is a co-relational study so the causal inference cannot be made between variables. Regarding clinical variables only age of onset of illness and duration of illness are considered. In some socio-demographic variables gross difference has been found between categories and applying non-parametric statistical test to those variables can limit the statistical power. The FACIT-SP-12 scale to assess spirituality is applied only in few studies concerning mental health specifically in the population of schizophrenic patient, so the comparison and substitution of results found to be difficult.

\section{Clinical Implication}

Results can have indirect but important implications for clinical practice. Improving quality of life is a holistic approach in treatment process of psychiatric disorders. Spirituality can help to cope with stresses in life and improve mental health. Clinicians might be helpful in understanding patient's spiritual dimensions and to incorporate in therapeutic process.

\section{Acknowledgments}

The author appreciates all those who participated in the study and helped to facilitate the research process.

Conflict of Interests: The author declared no conflict of interests. 


\section{Relationship between Insight and Spirituality in Individuals with Schizophrenia}

\section{REFERENCES}

Amador, X. F., \& Gorman, J. M. (1998). Psychopathologic domains and insight in schizophrenia. Psychiatr Clin North Am, 21(1), 27-42.

Ampalam, P., Deepthi, R., \& Vadaparty, P. Schizophrenia - insight, depression: a correlation study. Indian J Psychol Med, 34(1), 44-48.

Birchwood, M., Smith, J., Drury, V., Healy, J., Macmillan, F., \& Slade, M. (1994). A self-report Insight Scale for psychosis: reliability, validity and sensitivity to change. Acta Psychiatr Scand, 89(1), 62-67.

Jason M. Bredle., John M. Salsman., Scott Debb., Benjamin J. Arnold and David Cella (2011) "Spiritual Well-being as a Component of Health-Related Quality of Life: The functional Assessment of chronic illness Therapy- Spiritual Well-Being Scale (FACIT-Sp), Religion, ISSN 2077-1444, Vol. 2, 77-94.

Josephson, A. M., \& Dell, M. L. (2004). Religion and sprituality. Child Adolesc Psychiatr Clin N Am, 13(1), xv-xvii.

Karow, A., \& Pajonk, F. G. (2006). Insight and quality of life in schizophrenia: recent findings and treatment implications. Curr Opin Psychiatry, 19(6), 637-641.

Karow, A., Pajonk, F. G., Reimer, J., Hirdes, F., Osterwald, C., Naber, D., et al. (2008). The dilemma of insight into illness in schizophrenia: self- and expert-rated insight and quality of life. Eur Arch Psychiatry Clin Neurosci, 258(3), 152-159.

Koenig, H. G., \& Bonelli, R. M. Mental disorders, religion and spirituality 1990 to 2010: a systematic evidence-based review. J Relig Health, 52(2), 657-673.

Lysaker, P. H., Davis, L. W., Warman, D. M., Strasburger, A., \& Beattie, N. (2007). Stigma, social function and symptoms in schizophrenia and schizoaffective disorder: associations across 6 months. Psychiatry Res, 149(1-3), 89-95.

Lysaker, P. H., Vohs, J. L., \& Tsai, J. (2009). Negative symptoms and concordant impairments in attention in schizophrenia: associations with social functioning, hope, self-esteem and internalized stigma. Schizophr Res, 110(1-3), 165-172.

Mueller, P. S., Plevak, D. J., \& Rummans, T. A. (2001). Religious involvement, spirituality, and medicine: implications for clinical practice. Mayo Clin Proc, 76(12), 1225-1235.

Ruesch, P., Graf, J., Meyer, P. C., Rossler, W., \& Hell, D. (2004). Occupation, social support and quality of life in persons with schizophrenic or affective disorders. Soc Psychiatry Psychiatr Epidemiol, 39(9), 686-694.

Singh, S. K., Fischer, U., Singh, M., Grebe, M., \& Marchant, A. (2008). Insight into the early steps of root hair formation revealed by the procuste1 cellulose synthase mutant of Arabidopsis thaliana. BMC Plant Biol, 8, 57.

Stojkovic et al. Faith and adjustment to chronic diseases. SEEHSJ 2012; 2(1):52-61.

Young, R. \& Rohrer, J. E. (2004). Self-esteem, stress and self-rated health in family planning clinic patients. BMC Fam Pract, 5, 11.

How to cite this article: Phukan D, Dutta M (2017), Relationship between Insight and Spirituality in Individuals with Schizophrenia, International Journal of Indian Psychology, Volume 4, Issue 2, No. 92, ISSN:2348-5396 (e), ISSN:2349-3429 (p), DIP:18.01.106/20170402, ISBN:978-1-365-78192-6 